\title{
Geometria com animações interativas
}

\author{
Carlos Eduardo Souza* - carlos. ferreira @ ufrgs .br \\ Maria Alice Gravina** - gravina @ mat .. ufrgs .br \\ Instituto de Matemática, UFRGS
}

\begin{abstract}
Resumo
Os alunos do Curso de Licenciatura em Matemática da UFRGS tem no seu primeiro ano de curso uma disciplina que trata da geometria euclidiana e demonstrações de teoremas. As dificuldades apresentadas pelos alunos nos levaram a considerar os processos cognitivos que acompanham as situações de aprendizagem, bem como o importante papel da representação semiótica. Como resultado desta investigação foi produzido o objeto de aprendizagem "Geometria Plana", o qual pode ser considerado uma animação interativa, que faz uso de sistema dinâmico de representação semiótica. $\mathrm{O}$ objeto foi testado e os resultados indicam progressos dos alunos quanto ao desenvolvimento de habilidades para produzirem suas próprias demonstrações.
\end{abstract}

Palavras-chave de aprendizagem.

geometria, processo de aprendizagem, sistemas semióticos dinâmicos, objeto

\section{Geometry with interactive animations}

\begin{abstract}
Undergraduate preservice teachers in mathematics at Universidade Federal do RGSBrazil must follow a course on euclidian geometry in their first year. The difficulties among the students in the course has lead us to consider the cognitive process that underline the learning situations, as well the important role of semiotic representation. As result of this investigation, it was produced the learning object "Plane Geometry" which can be identified as an interactive animation that makes use of a dynamical semiotic system of representation. The object was tested in the mention course and the results showed an improvement of students' abilities for producing their own proofs.
\end{abstract}

\section{Keywords} geometry, learning process, dynamic semiotic systems, learning object

\section{Introdução}

$\mathrm{Na}$ área da Educação Matemática, a pesquisa na linha de processos cognitivos e aprendizagem bem documenta as recorrentes dificuldades enfrentadas pelos alunos que se iniciam no estudo da geometria ${ }^{1}$, quando entendida como modelo teórico que se organiza através de noções e relações primitivas, axiomas, teoremas e demonstrações.

\footnotetext{
* Aluno do curso de Bacharelado em Matemática da UFRGS, responsável pelo design gráfico e programação do objeto de aprendizagem "Geometria Plana".

** Professora do Curso de Licenciatura em Matemática e do Programa de Pós-Graduação em Ensino de Matemática, responsável pela concepção pedagógica do objeto de aprendizagem "Geometria Plana".
} 
Além das dificuldades que são inerentes ao entendimento do significado de demonstrar um teorema e ao desenvolvimento de habilidades necessárias para a produção de demonstrações, os alunos tem uma adicional dificuldade que advém da tradicional forma de apresentação do saber matemático. No geral, os alunos não apresentam a maturidade matemática necessária para o entendimento de idéias importantes e centrais, que constituem a demonstração de um teorema, especialmente quando apresentada através do texto e do desenhos estáticos, característicos dos livros de Matemática.

As mídias digitais podem contribuir na superação desta adicional dificuldade. Através da sincronização de figuras dinâmicas e manipuláveis com o texto que apresenta a argumentação dedutiva, torna-se possível a veiculação de idéias e argumentos matemáticos, com uma transparência que pode contribuir tanto para $\mathrm{o}$ entendimento das demonstrações dos teoremas como para a desenvoltura no uso da linguagem matemática.

É neste espírito que desenvolvemos o objeto de aprendizagem "Geometria Plana", consistindo de coletânea de teoremas na forma de animações interativas. No produto final procuramos garantir uma das importantes características de um objeto de aprendizagem - aquela de oferecer interface com recursos para um aprendizado autônomo - tornando-se assim um material que também pode ser utilizado em programas de educação a distancia.

Visando colocar em relevância os princípios que definiram a implementação do objeto, apresentamos inicialmente considerações sobre o processo de aprendizagem da geometria e o importante papel da linguagem matemática a ele associado.

\section{Sobre a aprendizagem da geometria e a representação semiótica}

O processo de demonstração é central na construção de conhecimento em Geometria e e' um dos aspectos que apresenta obstáculos aos alunos, como atestam pesquisas desenvolvidas na área (Balacheff, 1987, 1999; Moore, 1994) e situações de aprendizagem acompanhadas em disciplina de primeiro semestre do curso de Licenciatura em Matemática da UFRGS (Gravina, 1996, 2001).

Uma das dificuldades aparece na transição, necessária, entre o conhecimento de natureza empírica, já adquirido, e aquele a ser construído: a geometria euclidiana enquanto corpo teórico, organizado em axiomas, teoremas e demonstrações, e definições. O conhecimento empírico constitui-se a partir das impressões e experiências proporcionadas pelo mundo sensível imediato. É a partir da regularidade das formas aí presentes que são construídas as primeiras abstrações geométricas, caracterizadas sobremodo por impressões visuais, onde círculos, quadrados, retângulos são nomes que simplesmente identificam formas. As experiências escolares de medições e manipulações empíricas suportam a primeira identificação das propriedades geométricas. Por exemplo: quando os alunos manipulam triângulos, medem e somam os ângulos de diferentes triângulos e então generalizam: "a soma dos ângulos de um triângulo é sempre igual à 180 graus". Ou seja: aqui não está em jogo a aprendizagem direcionada à construção de conhecimento de natureza hipotético-dedutiva, uma característica da geometria euclidiana.

A ascensão a novo patamar de conhecimento - do que poder-se-ia classificar como sensorial e prático àquele que depende de raciocínios sobre objetos abstratos, raciocínios a estabelecerem relações de caráter necessário e ou suficiente entre fatos geométricos - exige raciocínios lógico-dedutivos, nem sempre 
espontâneos. Neste novo estágio - o estudo da geometria hipotético-dedutiva - o que até então era aceito como intuitivamente plausível deve agora ser explicado mediante demonstração. Trata-se agora de construção de conhecimento sintonizado à geometria enquanto área de saber matemático, concomitante ao desenvolvimento do pensamento de natureza geométrica. Por pensamento geométrico entendemos os raciocínios de natureza dedutiva e visual que manipulam desenhos inseridos num quadro conceitual bem definido - são os teoremas e demonstrações deduzidos, por via de regras de inferência lógica, a partir de alguns poucos pressupostos que a intuição não coloca em questão, os axiomas.

É através do referencial teórico vygotskiano que trazemos a relevância da linguagem matemática neste processo de aprendizagem. Em Vygostsky (1978) tem-se, de modo enfático, o papel da linguagem no desenvolvimento das funções psicológicas superiores. É esclarecedora e interessante a sua analogia:

"A invenção e o uso dos signos como meios que dão suporte a resolução de um dado problema psicológico ( comparar, reportar, analisar, escolher, entre outras ações mentais) é análogo a invenção e o uso de ferramentas, em certo aspecto. Os signos funcionam como instrumentos para atividade psicológica de modo análogo ao papel das ferramentas no trabalho"

De forma similar, tem-se no sistema de representação usado na geometria na forma de linguagem natural ou simbólica e de desenhos - uma ferramenta de suporte à construção do conhecimento. É com o domínio deste sistema de representação que criam-se as condições para a internalização discutida por Vygostsky - um processo de natureza sócio-cultural que transforma experiências individuais interpessoais em experiências intrapessoais. E' o sistema de representação que vai dar suporte aos processos cognitivos que levam ao entendimento do significado de uma demonstração e ao desenvolvimento das habilidades que concorrem para a produção de demonstrações.

É de forma recorrente que encontramos na literatura, que documenta a pesquisa em Educação Matemática, referências ao importante papel dos sistemas de representação semiótica no processo de aprendizagem da Matemática ${ }^{2}$. Conforme Ernest (2006), sendo a semiótica o estudo dos signos que participam em diferentes contextos das atividades humanas, é natural considerar o processo de aprendizagem da Matemática também sob esta perspectiva. Desta forma, além do olhar sobre os processos cognitivos que levam a construção do conhecimento, tem-se também o olhar sobre o processo (complexo) de apropriação de um sistema semiótico (até então simplesmente referido como linguagem matemática) nas situações de aprendizagem da Matemática, o que indica um posicionamento epistemológico de natureza socioconstrutivista.

Ernest avança na definição do que seria um sistema semiótico no contexto específico da Matemática, explicitando três componentes: um conjunto de símbolos que são expressos através da fala ou do texto, e do desenho; um conjunto de regras de produção de signos, incluindo aqui aquelas que tratam da organização do discurso que faz uso da composição de signos; um conjunto de relações entre os signos e seus significados, dependente de uma subjacente estrutura de significados. Esta definição procura abarcar as características dos textos, símbolos e desenhos que se integram no discurso lógico que produz e cristaliza o conhecimento matemático.

A complexidade do sistema de representação semiótica, em particular no contexto da geometria, pode nos ajudar a entender as recorrentes e equivocadas manifestações dos alunos, quando em situação de aprendizagem. E' assim que, por exemplo, os alunos tomam como propriedade do segmento altura de um triângulo o "ser 
um segmento no interior do triângulo", ou que referem ao paralelogramo como o "quadrilátero com dois ângulos agudos e dois obtusos"”. Outra dificuldade clássica, registrada em diversos momentos na literatura, é quanto a ordenação por inclusão na família dos quadriláteros: os quadrados não são reconhecidos como subclasse dos retângulos, nem os retângulos como subclasse dos paralelogramos.

Em casos extremos, os alunos até mesmo confundem características físicas do desenho - espessura do traçado, tamanho do ponto - com propriedades geométricas, e assim dizem que "os círculos tangentes se interceptam em infinitos pontos" (Gravina, 1996) ou que o "ponto de intersecção de duas retas é menor que o ponto de interseção de três retas"(Fischbein, 1994). Estes exemplos ilustram, de forma contundente, a atribuição de significados que fogem do domínio de funcionamento do sistema de representação semiótica - o desenho "escapa" do significado que lhe é atribuído no sistema de representação utilizado na Geometria.

As mídias digitais potencializam novas possibilidades para os sistemas de representação semiótica. Os sistemas se tornam dinâmicos e desta forma facilitam o processo de apropriação de seu funcionamento, nos três componentes já destacados: signos, regras de produção de signos e relações entre signos e significados.

Na perspectiva de Levy (1993), diríamos que os sistemas dinâmicos de representação semiótica são tecnologias da inteligência que, por um lado concorrem para interiorização de saberes através de suporte mais versátil, e por outro lado permitem externar explorações e investigações que se apresentam mais próximas dos bastidores da atividade intelectual, concorrendo para uma aproximação entre as idéias que são a essência do saber matemático e a representação semiótica que procura registrar estes saber ${ }^{4}$.

É interessante também observar o grande impacto destes sistemas de representação no contexto da pesquisa em Matemática, dado pelo desenvolvimento de softwares dirigidos para visualização matemática - na tela do computador tem-se representações dinâmicas processos matemáticos, dadas através de animações interativas. Nos diz Palais (1999): "conforme a matemática se torna mais e mais complexa, torna-se cada vez mais importante ter-se ferramentas que suplementem nossa intuição e que nos ajudem a comunicar nossa idéias intuitivas"(p. 657).

Para o aprendizado da geometria temos softwares que disponibilizam sistemas dinâmicos de representação semiótica - são os ambientes de geometria dinâmica. Nesses ambientes os objetos construídos, com régua e compasso virtuais, podem ser manipulados diretamente na tela do computador, imprimindo-se desta forma dinamismo às configurações. O "desenho em movimento" torna-se revelador dos invariantes que são decorrências implícitas da construção feita. De imediato percebe-se uma das potencialidades destes ambientes: ao oferecer um sistema de representação semiótica que agrega a manipulação dinâmica aos objetos concreto-abstratos (a representação na tela do computador concretiza um objeto geométrico que é abstrato), ele desencadeia algumas das primeiras ações mentais características do raciocínio geométrico - o de estabelecer relações entre os objetos geométricos - e o faz de forma contundente, se comparado às possibilidades apresentadas no sistema de representação que faz uso do desenho estático em papel.

Pesquisas atestam o potencial desses ambientes, sobretudo no aspecto concernente à construção de conceitos em geometria: construtos individuais, até então deformados por imagens prototípicas, são reconstruídos através do "desenho em movimento", colocando em sintonia os significados individuais e os significados inseridos na geometria enquanto teoria matemática. ${ }^{5}$ Pesquisas também indicam que os alunos sentem-se mais motivados a buscar explicações para conjeturas formuladas em 
função de suas manipulações sobre os objetos geométricos dinâmicos e das evidências que daí emergem. (Jiang \& Mcclintock,1997; Keyton, 1997)

Quanto ao processo de demonstração, muitas são as questões em aberto, dentre elas: de que forma os ambientes de geometria dinâmica podem desencadear, para além de situação de experimentação (os ambientes tem, de imediato, o caráter de 'laboratório de experiências'), a argumentação dedutiva? Em Gravina(2001) apresentamos uma engenharia didática que tem como propósito a implementação de situações de aprendizagem voltadas, inicialmente, para o entendimento do significado de uma demonstração e depois voltadas para o desenvolvimento de habilidades para produção de demonstrações. Na engenharia proposta é de crucial importância o papel do professor quanto a institucionalização do conhecimento produzido pelos alunos, de forma a ajudá-los na apropriação do sistema de representação semiótico (texto, símbolos e desenhos) que dá suporte a produção do raciocínio dedutivo.

Procurando tirar proveito das animações interativas que podem ser hoje produzidas, através de linguagem de programação voltadas a objetos, desenvolvemos uma coletânea de teoremas e demonstrações. Nosso propósito foi disponibilizar um produto que provoca o desenvolvimento de habilidades para a produção de demonstrações em geometria, através de apresentação que atenta para o necessário processo de apropriação de um sistema de representação semiótica. Este produto se caracteriza como um objeto de aprendizagem, conforme veremos na próxima seção.

\section{O objeto de aprendizagem "Geometria Plana",}

As considerações feitas na seção anterior justificam o princípio geral que norteou a concepção e a implementação do objeto de aprendizagem "Geometria Plana": ser um recurso que provoque no aluno, através de utilização autônoma, o desenvolvimento de habilidades para a produção de demonstrações.

A estratégia utilizada para a produção da coletânea de teoremas está em sintonia com as considerações teóricas de Wiley (2009), no que diz respeito ao elenco de características que deve ter-se em um objeto de aprendizagem: "ser um recurso digital que pode ser reusado no suporte ao aprendizado"(pg.7). Nesta definição, ao colocar a expressão "suporte ao aprendizado", Wiley procura capturar não só o que explicita como importantes atributos de um objeto (reusável, digital, recurso, aprendizagem), mas também procura destacar que deve haver no objeto uma intencionalidade quanto ao processo de aprendizagem.

Wiley reforça esta importante característica de "intencionalidade" ao assumir uma posição crítica quanto a produção, em profusão, de recursos digitais que vem sendo referidos como "objetos de aprendizagem", mas que servem tão somente para a "glorificação do ensino on-line, da mesma forma que clip-art e dingbats são usados, freqüentemente sem maior intenção, para decorar jornais de notícias das escolas".

Ainda segundo Wiley, a agregação de "intencionalidade de aprendizagem" ao objeto depende de processo de concepção que se insere em arcabouço teórico que leva em consideração a situação de aprendizagem pretendida, para então serem definidos os aspectos relativos a implementação tecnológica.

No que segue descrevemos o processo de concepção e implementação do objeto. Dois foram os focos de pesquisa - um pedagógico e outro técnico-informático. Sob o ponto de vista pedagógico, definimos as características de interface de forma a atender o princípio geral apresentado no início desta seção: a) ser material que organiza teoremas e demonstrações; b) ser material que permita sincronizar o ritmo de apresentação dos teoremas e demonstrações com o ritmo de aprendizagem do aluno; c) ser material que permite a aprendizagem com autonomia, através de recursos para manipular as figuras geométricas que estão na tela do computador. Sob o ponto de vista técnico, tratamos de definir o recurso a ser usado - no caso uma linguagem de programação orientada a objetos ${ }^{7}$, de forma a garantir uma implementação com a intencionalidade de aprendizagem descrita nos itens listados acima. 
A partir da definição dos aspectos pedagógicos e técnicos foi iniciado o processo de implementação do objeto, e procuramos tirar o máximo proveito dos recursos de programação de modo a ter-se no objeto ,na medida do possível, uma transparência quanto ao uso do sistema de representação semiótica. Os signos, as regras de uso dos signos e as relações entre signos e significados estiveram sob constante atenção de forma a ter-se um padrão de apresentação do texto e das figuras que dão suporte a demonstração de um teorema. Na Figura 1 temos uma tomada de instâncias do "Teorema das soma dos ângulos de um triângulo",onde ilustramos o uso do texto e signos, de texturas e cores no desenho, de forma a esclarecer o fluir da argumentação dedutiva.
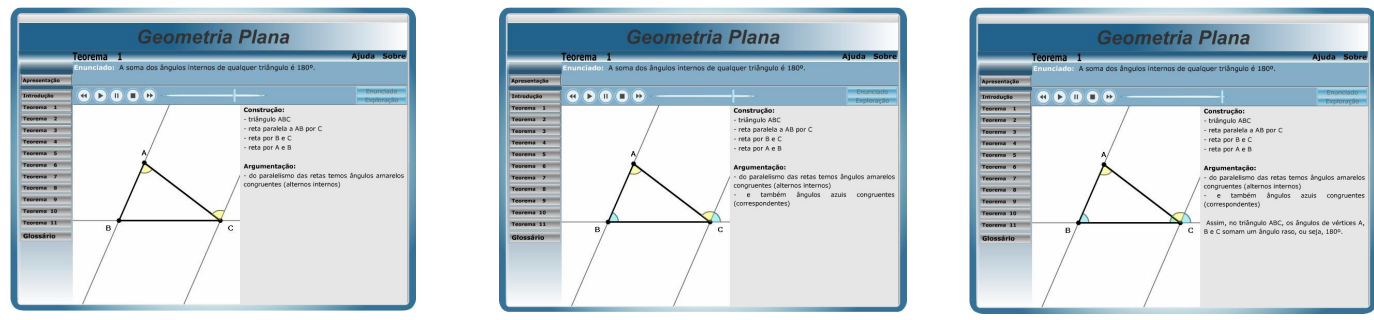

Figura 1 - O uso dos signos, da textura e das cores

Além disto, foram usados recursos de programação que agregam ao objeto a característica de ser uma animação interativa. Isto significa que o aluno pode manipular livremente, em qualquer momento da apresentação da animação, a figura acompanhada pelo texto discursivo dá suporte a argumentação dedutiva. Com este recurso, o aluno interage com diferentes instancias da figura, e desta forma evita as dificuldades (clássicas na literatura), advindas do uso de figuras prototípicas, fortemente associadas a sistema de representação semiótico estático dos tradicionais livros de geometria.

A navegação no objeto se organiza através do seguinte menu: a) "Apresentação"explica as possibilidades de interação; b) "Introdução" - apresenta os fundamentos da Geometria Euclidiana, quanto a organização do conhecimento através de axiomas, definições e teoremas; c) "Coletânea de Teoremas" - são os onze teoremas que constituem o material pedagógico; d) "Glossário" - apresenta os conceitos utilizados nos teoremas e demonstrações.

Na Figura 2, através de tela que trata do Teorema das Medianas de um triângulo, ilustramos o funcionamento do objeto:

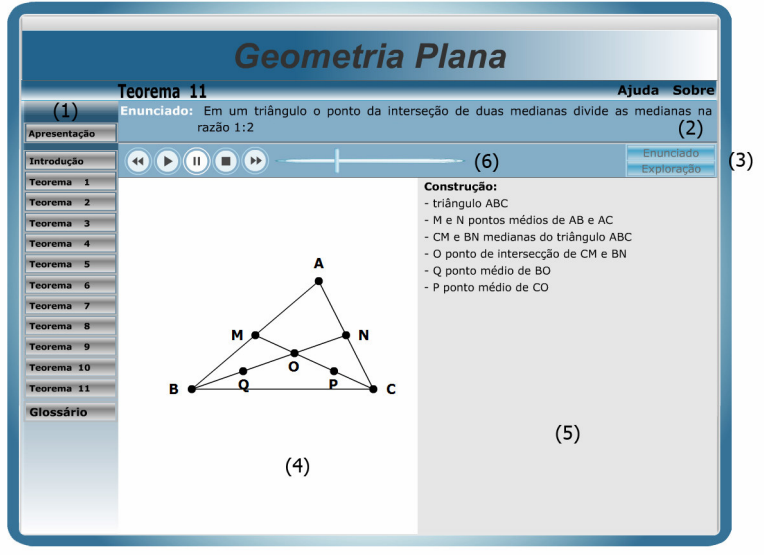

Figura 2 - O funcionamento do objeto

- tem-se botões que ao serem clicados disponibilizam o enunciado do teorema ( em (2)) e sua demonstração ( em (3)) 
- ao selecionar o botão de demonstração, tem-se no objeto a marcação de dois espaços - à esquerda é a construção da figura que vai dar suporte a demonstração (em (4)) e à direita, em (5), de forma sincronizada, é a apresentação do texto que registra os passos da construção e a argumentação dedutiva (em(5)).

- o procedimento de construção acompanhado de texto se desenrola, intencionalmente, de forma automática, provocando o aluno a acompanhar o ritmo do discurso argumentativo que caracteriza a demonstração de um teorema. Mas tem-se a opção de graduar a velocidade do ritmo, bem como fazer pausas ao longo da apresentação, usando a barra de opções, em (6).

O objeto "Geometria Plana" foi testado com alunos calouros do Curso de Licenciatura em Matemática , no primeiro semestre de 2009, em disciplina que trata de demonstrações de teoremas da geometria euclidiana. Estes alunos iniciaram a disciplina com pouca desenvoltura em raciocínio de natureza dedutiva, pois na escola pouco se trabalha com demonstrações, conforme atestam as pesquisas (Pavanello, 1993) e também os livros didáticos utilizados. E' assim que os alunos chegam na universidade

No início da disciplina os alunos trabalharam com software de geometria dinâmica, com o propósito de construir figuras geométricas e identificar: a) os fatos geométricos explícitos - aqueles declarados na construção; b) os fatos geométricos implícitos - aqueles que não foram declarados, mas que são evidenciados com a manipulação da representação semiótica dinâmica. A título de exemplo, na construção ilustrada na Figura 3, ao final tem-se um quadrilátero onde os fatos explícitos são: $\mathrm{AB}$ e $\mathrm{AD}$ segmentos congruentes e ângulos de vértices $\mathrm{A}$ e $\mathrm{B}$ retos. Os fatos implícitos a serem demonstrados, de forma a garantir um quadrado como resultado da construção são: segmentos $\mathrm{AB}, \mathrm{BC}$ e $\mathrm{CD}$ congruentes e ângulos de vértices $\mathrm{C}$ e $\mathrm{D}$ retos.

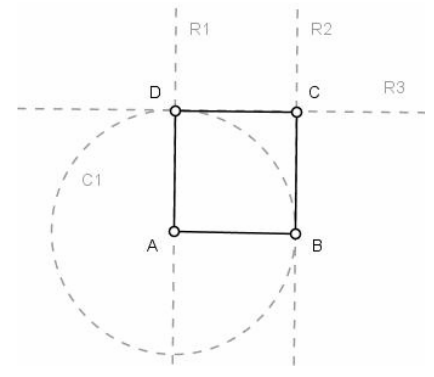

Passos da construção:

- segmento $\mathrm{AB}$

- reta $\mathrm{R} 1$ perpendicular à $\mathrm{AB}$ por $\mathrm{A}$

- reta $\mathrm{R} 2$ perpendicular à $\mathrm{AB}$ por $\mathrm{B}$

- círculo C 1 de centro A por B

- D ponto de intersecção de $\mathrm{R} 1$ e $\mathrm{C} 1$

- reta $\mathrm{R} 3$ paralela à $\mathrm{AB}$ por $\mathrm{D}$

- C ponto de intersecção de R2 e R3

\section{Figura 3 - Uma construção geométrica}

Com esta atividade inicial os alunos foram preparados para entender o significado de uma demonstração, o que justifica a apresentação de um argumento que explica, a partir dos fatos que foram explicitados, os fatos que estão implícitos na construção. Criada esta condição de entendimento, os alunos iniciaram o trabalho com o objeto de aprendizagem "Geometria Plana", sem que neste momento houvesse qualquer intervenção do professor. A sincronização da construção com o texto discursivo, com gradativa apresentação dos novos elementos geométricos, destacados através de textura e cores, agregada a possibilidade de controlar o avanço/recuo e a velocidade do desenrolar da animação tornaram o objeto um suporte para a internalização do saber geométrico que se apresenta como modelo teórico axiomático.

Os resultados obtidos sinalizam o desenvolvimento de habilidades que são necessárias para a produção autônoma de demonstrações. Os alunos se manifestaram, após a utilização do objeto :

"Além de entendermos com clareza os passos da construção, podemos interagir com ela. Houve um a clareza melhor sobre congruências e como demonstrar os teoremas." 
"(O objeto $)$ é uma ótima ajuda na visualização e na forma com que a argumentação deve ser feita. Auxiliou-me muito no raciocínio referente a tais figuras."

"Podemos aprender a demonstrar com o objeto, pois além de ele ser prático e de fácil manuseio, é também objetivo. Podemos entender as explicações e demonstrações."

"O objeto facilita a visualização dos teoremas."

"O objeto é interessante, pois além de acompanhar a explanação do teorema , aprendemos os passos de cada construção."

\section{Conclusões}

Nossa experiência na produção do objeto "Geometria Plana" mostra o quão importante é considerar, no processo de implementação, as inter-relações entre aspectos pedagógicos e tecnológicos, de forma a ter-se um produto com as características de um objeto de aprendizagem. Isto porque as soluções técnicas e pedagógicas se realimentam, e assim se fez necessário um período inicial de muita exploração de programação visando testar os resultados pedagógicos que se concretizavam no objeto. Este tempo de pesquisa foi valioso, pois significou uma grande economia de esforços na continuidade da implementação do objeto. Foi após muitas experiências iniciais que foram gerados algoritmos para a criação de campos interativos de exploração e de demonstração dos teoremas e que também foi feita uma padronização de interface. Assim temos agora um "esqueleto básico", integrando aspectos pedagógicos e técnicos, a partir do qual estaremos expandido o objeto com a apresentação de teoremas que são profundos em idéias matemáticas. São teoremas que normalmente não são apresentados nos curso introdutórios, mas estamos apostando que através do uso de sistemas dinâmicos de representação semiótica as idéias podem se tornar transparentes e acessíveis para alunos que se encontram ainda no início de seus estudos em geometria.

\section{Referências Bibliográficas}

BALACHEFF, N. Processus de Preuve et Situations de Validation, Educational Studies in Mathematics, vol. 18, Dordrecht: Kluwer Academic Publisher, 1987.

BALACHEFF, N. Apprendre la preuve, em Sallantin J., Szczeciniarz J.-J. (editores), Le concept de preuve à la lumière de l'intelligence artificielle, Paris : PUF, 1999.

ERNEST, P. A semiotic perspective on Mathematical Activity. Educational Studies in Mathematics, vol. 61, Dordrecht: Kluwer Academic Publisher, 2006.

FISCHBEIN, E. The theory of figural concepts, Educational Studies in Mathematics, vol. 24/2, Dordrecht: Kluwer Academic Publisher, 1994.

GRAVINA, M. A .Os ambientes de geometria dinâmica e o pensamento hipotetico dedutivo,Tese de doutorado no Programa de PósGraduação em Informática na Educação/UFRGS, disponível em http://www.biblioteca.ufrgs.br/bibliotecadigital/, 2001.

GRAVINA, M. A. Geometria Dinâmica: uma nova abordagem para o aprendizado da Geometria em Anais do VII Simpósio Brasileiro de Informática na Educação, Belo Horizonte, 1996.

LEVY, P. L'Idéographie Dynamique: vers une Imagination Artificielle? Paris, França : Éditions La Découvert, 1991.

LEVY, P. Tecnologias da Inteligência: o futuro do pensamento na era da informática. São Paulo SP : Editora 34, 1993.

JIANG, Z. e McCLINTOCK, E.: Using The Geometer's Sketchpad with Preservice Teachers, em King, J. e Schattschneider, D. (editores), Geometry Turned On, Mathematical Association of America Notes 41, Washington, USA : The Mathematical Association of America, 1997.

KEYTON, M.: Students Discovering Geometry Using Dynamic Geometry Software, em King, J. e Schattschneider, D. (editores),. Geometry Turned On, Mathematical Association of America Notes 41, Washington, USA : The Mathematical Association of America, 1997. 
MOORE, R. Making Transition to Formal Proof, Educational Studies in Mathematics, vol. 27, Dordrecht: Kluwer Academic Publisher, 1994.

PALAIS, R. The visualization of mathematics. Notices of the MAS, vol. 46, $\mathrm{n}^{\circ}$ 6, 1999 ,

PAVANELLO, R.M. O abandono do ensino da geometria no Brasil, causas e conseqüências, Revista Zetetiké, ano 1, vol. 1, Campinas: Editora UNICAMP, 1993.

VYGOTSKY, L. S. Mind in society: The development of higher psychological process. Cambridge, MA: Harvard University Press, 1978.

WILEY, D. A . Connecting learning objects to instructional design theory : a definition, a metaphor and a taxonomy. Disponível em : $\mathrm{http}$ ://reusability.org/read/chpters/wiley.doc. Acesso em $27 \mathrm{de}$ maio de 2009.

\section{Notas}

${ }^{1}$ A referência à geometria deve ser entendida sempre como sendo geometria euclidiana.

${ }^{2}$ Vale aqui registrar que a revista Educational Studies in Mathematics publicou no ano de 2006 uma edição especial intitulada Semiotic Perspectives on Epistemology and Teaching and Learning of Mathematic

${ }^{3}$ Por definição: a) a altura relativa à um dos lados de um triângulo é o segmento $\mathrm{AB}$, onde $\mathrm{A}$ é vértice oposto ao lado em questão e B é o pé da reta perpendicular que intercepta o lado e passa por A; b) um paralelogramo é um quadrilátero com lados opostos paralelos.

${ }^{4}$ E' interessante registrar as considerações de Levy, no seu livro Idéographie Dynamique” , ainda que no terreno da especulação, sobre as potencialidades das tecnologias da inteligência na implementação de uma nova linguagem - a ideografia dinâmica (idéographie dynamique). Esta linguagem seria uma tecnologia de apoio à imaginação, ao raciocínio e à comunicação, diferente das linguagens escritas até então disponíveis, constituindo-se de signos dinâmicos, impregnados de significação em seus movimentos e metamorfoses. Com a ideografia dinâmica, dispor-se-ia de um meio de registro dos funcionamentos cognitivos associado à modelos e imagens mentais, entendendo-se por modelo uma estrutura organizada composta de ideogramas, a guardar relações entre os componentes; e por, imagem, uma instância de representação do modelo, impregnada de significação no seu dinamismo. Raciocinar sobre determinado problema significaria construir e manipular modelos mentais da situação sob exame, tendo-se como suporte a tecnologia informática; compreender uma teoria significaria a interiorização de modelos já construídos; e comunicar significaria estabelecer sintonia entre modelos mentais, passíveis de serem concretizados.

${ }^{5}$ A título de exemplo: feita a construção de um paralelogramo que seja estável sob ação de movimento, ao deslocarem-se os vértices que são livres, obtém-se transformações no paralelogramo e na tela têm-se os casos particulares de retângulo e quadrado, evidenciando-se que tais figuras são subclasses dos paralelogramos, e com isso construtos prototípicos dos alunos — tipo "quadrado não é paralelogramo" se modificam

${ }^{6} \mathrm{O}$ objeto de aprendizagem "Geometria Plana" está disponível on-line, sob o nome "Teoremas da Geometria Plana através de animações”, em

http: // www. edumatec .mat.ufrgs.br no link Atividades / Atividades Diversas em Geometria. Foi desenvolvido com o apoio da SEAD/UFRGS , no Edital $08 \mathrm{EAD}$, através de concessão de bolsa para aluno durante o ano de 2008.

${ }^{7}$ Foi utilizado o software Adobe Flash e a linguagem Actionscript 